\title{
Extraction and Concentration Comparison of Dyeing Behavior of Orange dye on Lyocell Fabric
}

\author{
${ }^{a}$ Sayed Yaseen Rashdi, ${ }^{\mathrm{b} *}$ Zamir Ahmed Abro, ${ }^{\mathrm{c}}$ Abdul Malik Rehan Abbasi, ${ }^{\mathrm{c}}$ Ahmer Hussain Shah, ${ }^{\mathrm{b}}$ Azmat Hussain, ${ }^{\mathrm{c}}$ Syed \\ Zameer-Ul-Hassan
}

a: College of Chemistry, Chemical Engineering and Biotechnology, Donghua University, Shanghai, China

b: College of Textiles, Donghua Univeristy,Shanghai, China

c: Department of Textile Engineering, BUITEMS, Quetta

* Corresponding Author: zamirabro@ hotmail.com

\begin{abstract}
Natural dyes are widely considered for their environmental properties and ease of use. In this study, Lyocell fabrics were dyed with natural dyes, extracted by peeling oranges, and evaluated comparatively based on color efficiency (K/S), CIE $L^{*} a^{*} b^{*}$ values, and fastness. Re-infer minerals using metal (II) sulfates and copper sulfate (II). In order to extract the dye, the standard technique of water extraction is used. The dyeing effect of Lyocell fabric was checked at $2 \%$ and $4 \%$ by the method of pre-immersion and postimmersion. The study found that this seasoning affects the efficiency of the color of the fabric dyed with orange peel. All dyed samples showed better, better color efficiency (K/S: 4.57) at $4 \%$ concentration levels during the post- mordanting processing (K/S: 4.57), color fastness of washing, light, and friction, and sweat. In general, the post- mordanting method at the $4 \%$ concentration level has a significant effect on color efficiency and color fastness characteristics.
\end{abstract}

Key Words: Natural dyes, Orange Peel, Lyocell, Extraction, Mordant, Colorfastness.

Date Received 07 Sep 2019

Date Accepted 20 Dec 2019

Date Published 25 June 2020

\section{INTRODUCTION}

Since 1856, the use of synthetic dyes has opened enormous $N_{\text {benefits to apply depth colors to the textiles due to their }}$ light weight, ease of processing, quite lower costs, and moderate-to-excellent color fastness properties [1]. However, their discarding process and petroleum source products have created severe hazardous to our environment due to their nonbiodegradable nature [2]. As a result, many countries have banned the use of various azo-based dyes (-N-) for their applications and manufacturing [3]. Substituting conventional synthetic dyes with natural dyes is an attractive interest to mitigate the problems mentioned above $[4,5]$.

Natural dyes hold great potential for sustainability, offering the possibility of renewability, biodegradable, and anti-allergic from harmful additives [6,7]. Moreover, they have a massive worth in the perspective of deteriorating conventional synthetic polymers and global warming associated with it [8]. Therefore have not any ecological issues. The natural dyes have been used for the coloring of textiles materials since the Bronze Age[9]. However, in this modern era, their applications and comprehensive usage have been developed towards UV protective clothing, antimicrobial finishing, food colorations, pharmaceuticals, and cosmetics. [10]. Moreover, the interest and demand in natural dyes are continuously increasing for the reason that it does not implicate any active acerbic and alkalis in their uses and fabrications [11].

The dyes which are derived from natural sources are known to be natural dyes [12]. They are colorants that are attained without applying any chemicals. Natural dyes have limitations of fastness like the yield of color, reproducibility in results, complicated dying procedure, and mixing [13]. Moreover, the dyes also have poor fastness as they have a very low affinity towards fibers [14]. Therefore mordants are applied with colors to increase the relationship with fibers for commercial production applications[15].

Mordants employ a significant role in giving actual color to the textiles. Mordant is an ingredient that produces not only chemical reactions but also bonds between dyes and fabrics. [16]. It also improves the color application performance of dyes and fibers by increasing attractiveness [20]. It gives different shades when applied in different percentages. Hence deliver an extensive variability of color shades with suitable intensities of colorfastness [17].

Lyocell is a regenerated cellulosic fiber prepared from wood pulp and is an fantastic natural fabric that specifies a high point in the progress of green sustainable textile [18]. Orange is one of the most common and famous fruit in the world, which yearly yield over 100 million tons[19]. Moreover, orange peel (OP), i.e., a shell of the orange fruit is the bioresource wastage and present in abundance [20]. The bright orange color extracted from OP generally originates from phenolic compounds and increases with its concentration [21]. Additionally, it has antimicrobial and UV-protection properties and for that reason, could be used as a natural dye or textile.

In this study, Lyocell fabrics were dyed with natural dyes extracted from orange peel. Besides, two agents (ferrous sulfate and copper sulfate) should be used to evaluate their excellent application in the use of Lyocell fabrics. 


\section{MATERIALS AND METHODS}

\section{A Materials}

1) Dye Plant: Orange fruits (named as Tangerine) were purchased from the local market of Songjiangin Shanghai, China.

2) Fabric: $100 \%$ Lyocell fabrics were dyed, which was purchased from a private textile company called Hangzhou Xinsheng Printing and Dyeing Co., Ltd. (Xiaoshan Hangzhou).

3) Chemicals: Workshop-grade metal salts, such as ferrous sulfate (II) (FeSO4.7H2O), are manufactured by Sino pharmaceutical Chemical Reagents. LTD) and (copper (II) sulfates, CuSO4.5H2O produced by Sino pharmaceutical Chemical Reagents. LTD) is used as a chemical agent.

4) Raw Material Preparation: Peels were removed from the oranges and washed with water for the removal of the dust or other for the fore. The washed peels were dried in the oven for 20 hours at the temperature of 30 c messily; the dried peels were achieved for the extraction process by the grinder machine. Figure 1 has delineated both of raw materials.

5) Equipment: Weight balance, water bath, Soxhlet extractor, water bed, empty oven, tint color.

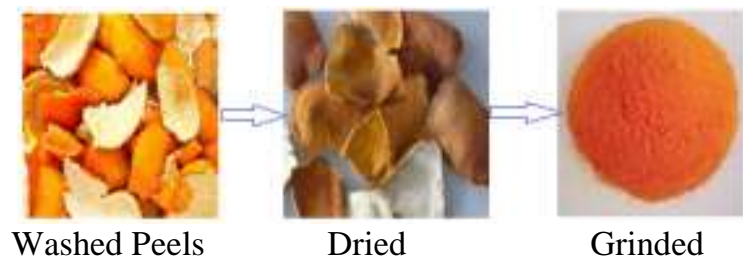

Figure 1 Preparation of Orange peel powder

\section{$B$ Methods}

1) Extraction of Natural Dyes: Water extraction is used to extract dyes from orange peel (OP). $10 \mathrm{~g}$ OP powder was taken from a round flask. The same container contains $200 \mathrm{ml}$ of distilled water. Besides, maintain a 1:20 material ratio to liquor (M.L.R). In a water bath, the flask is heated for 1 hour at a temperature of 90 degrees C. After the dye is extracted, the solution is filtered through Whatman filter paper for the dyeing process.

2) Mordanting: The Lyocell fabric sample was treated with two sulfates and copper sulfates at a temperature of 80 degrees $\mathrm{C}$ for 1 hour. Pre-immersion and postimmersion technology using liquor ratio 1:20. After the completion of Mordanting, the Lyocell fabric sample is washed and dried at a temperature of 26 degrees $\mathrm{C}$ and further used in the dyeing process.

3) Dyeing: Lyocell fabric samples were dyed by the exhaust method. Samples were also dyed at different concentrations ( $2 \%$ and $4 \%$ ) to compare the validity of the results. The sample was dyed for 1 hour with (M.L.R.; 1:40). Subsequently, the mordant fabric sample is cleaned with water and soap and tested after drying.

4) Characterization: According to ISO standards, different color fastness properties were tested for stained fabric samples, such as chromatogability to light (ISO 105-B02), washing (ISO 105-C01), friction (wet and dry) (ISO 105-X12) and sweat (ISO 105-E04). In addition, $\mathrm{k} / \mathrm{S}$ values are used to measure color strength and dye absorption.

\section{RESULTS AND DISCUSSIONS}

Orange peel was used for dyeing Lyocell fabric with two types of mordants i.e., ferrous sulfate and copper sulfate, at two different concentrations ( $2 \%$ and $4 \%$ ). With the similarly extracted dye, different shade colors were attained by changing mordants. Different fastness properties were assessed. Moreover, the pre-Mordanting and post-Mordanting methods were applied as a Mordanting process.

\section{Color Measurement and Dye Absorption}

$\mathrm{K} / \mathrm{S}$ values evaluated dye absorption and color shadow of dyed fabric samples. Measure the dye absorption concentration using the data color SF-600. Several different color ranges were found on Lyocell fabric Samples are carried out using $L^{*}, a^{*}, b^{*}, C^{*}, h^{*}$. Table 1 (a) shows with pre-Mordanting and post- Mordanting, the raw material s, and copper sulfate in the Lyocell fabric sample is dyed with $2 \%$ ferrous sulfate, and copper sulfate, while Table 1 (b) shows the dyeing of raw materials and different hues. Lyocell fabric samples containing ferrous sulfate and copper sulfate at a concentration of $4 \%$ using pre-Mordanting and post- Mordanting methods.

Table 1 (a) Color shades of Tencel fabric in pre and post Mordanting method on $2 \%$ concentration

\begin{tabular}{cccc}
\hline $\begin{array}{c}\text { Mordant } \\
\text { ing }\end{array}$ & Raw fabric & Ferrous Sulphate & Copper \\
Methods & & $\mathrm{FeSO}_{4}$ & Sulphate \\
$\mathrm{CuSO}_{4}$ \\
\hline
\end{tabular}

b
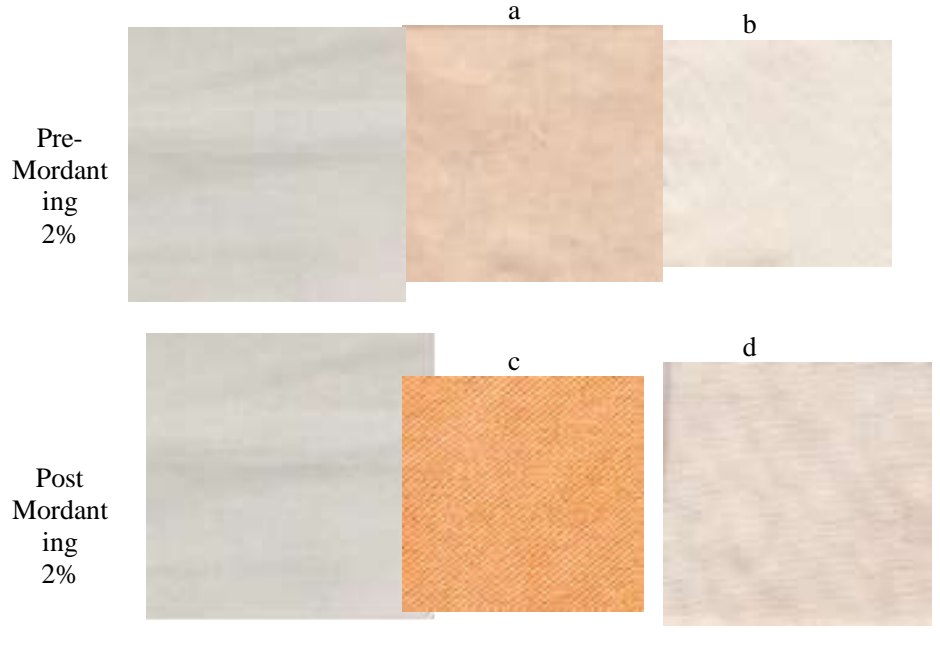
Table 1 (b) Color shades of Tencel fabric in pre and post Mordanting method 0n $4 \%$ concentration

\begin{tabular}{|c|c|c|c|}
\hline $\begin{array}{l}\text { Mordant } \\
\text { ing } \\
\text { Methods }\end{array}$ & Raw fabric & $\begin{array}{l}\text { Ferrous Sulphate } \\
\qquad \mathrm{FeSO}_{4}\end{array}$ & $\begin{array}{c}\text { Copper Sulphate } \\
\mathrm{CuSO}_{4}\end{array}$ \\
\hline \multirow{3}{*}{$\begin{array}{c}\text { Pre- } \\
\text { mordanti } \\
\text { ng } \\
4 \%\end{array}$} & & $\mathrm{a}$ & $\mathrm{b}$ \\
\hline & & & \\
\hline & & $\mathrm{c}$ & d \\
\hline $\begin{array}{c}\text { Post } \\
\text { mordanti } \\
\text { ng } \\
4 \%\end{array}$ & & & \\
\hline
\end{tabular}

Table 2 has shown the overall color shade and $\mathrm{L}^{*}, \mathrm{a}^{*}, \mathrm{~b}^{*}, \mathrm{C}^{*}$ and $h^{*}$ values. It has indicated that lower value of $\mathrm{L}^{*}$ has darker shades, and a higher value of $\mathrm{L}^{*}$ has lighter shade for Lyocell and likewise negative values of $a^{*}$ and $b^{*}$ denoted green and blue [40]. Furthermore, the highest color value (K/S $=4.56$ ) was obtained with ferrous sulfate at $4 \%$ concentration in the post-mordanting method and lowest color value $(\mathrm{K} / \mathrm{S}=$ 0.17 ) with copper sulfate at $4 \%$ concentration same in the post-mordanting method. The experimental outcomes indicated that the OP dye using ferrous sulfate in the postmordanting method with a concentration amount of $4 \%$ had delivered excellent results on Lyocell fabric.

Table 2 CIE L*a* $\mathrm{b}^{*} \mathrm{C} * \mathrm{~h} *$ AND K/S values of dyed Tencel fabric samples on both concentrations

\begin{tabular}{|c|c|c|c|c|c|c|c|}
\hline $\begin{array}{c}\text { Mordan } \\
t\end{array}$ & $\begin{array}{l}\text { Mordant } \\
\text { Method }\end{array}$ & $\mathbf{K} / \mathbf{S}$ & $\mathbf{L}^{*}$ & $\mathbf{a}^{*}$ & $b^{*}$ & $\mathrm{c}^{*}$ & $\mathbf{h}^{*}$ \\
\hline $\begin{array}{c}\mathrm{FeSO}_{4} \\
2 \%\end{array}$ & $\begin{array}{c}\text { Pre- } \\
\text { Mordantin } \\
\mathrm{g}\end{array}$ & 1.3752 & $\overline{-}$ & 5.37 & 20.82 & 21.48 & $0 . \overline{98}$ \\
\hline $\begin{array}{c}\mathrm{FeSO}_{4} \\
2 \%\end{array}$ & $\begin{array}{l}\text { Post- } \\
\text { Mordantin } \\
\mathrm{g}\end{array}$ & 3.475 & $\begin{array}{c}- \\
15.59\end{array}$ & 10.80 & 37.42 & 38.91 & $\begin{array}{c}- \\
1.56\end{array}$ \\
\hline $\begin{array}{c}\mathrm{FeSO}_{4} \\
4 \%\end{array}$ & $\begin{array}{l}\text { Pre- } \\
\text { Mordantin } \\
\mathrm{g}\end{array}$ & 2.0629 & 12.70 & 6.24 & 24.12 & 24.89 & $\overline{-}$ \\
\hline $\begin{array}{c}\mathrm{FeSO}_{4} \\
4 \%\end{array}$ & $\begin{array}{l}\text { Post- } \\
\text { Mordantin } \\
\mathrm{g}\end{array}$ & 4.5694 & $\begin{array}{c}- \\
17.21\end{array}$ & 12.21 & 41.23 & 42.97 & $\begin{array}{c}- \\
1.70\end{array}$ \\
\hline $\begin{array}{c}\mathrm{CuSO}_{4} \\
2 \%\end{array}$ & $\begin{array}{l}\text { Pre- } \\
\text { Mordantin } \\
\mathrm{g}\end{array}$ & 0.7058 & -5.25 & 1.38 & 11.92 & 12.00 & 0.09 \\
\hline $\begin{array}{c}\mathrm{CuSO}_{4} \\
2 \%\end{array}$ & $\begin{array}{l}\text { Post- } \\
\text { Mordantin } \\
\mathrm{g}\end{array}$ & 0.1953 & -2.12 & -4.40 & 1.31 & 3.41 & 3.07 \\
\hline $\begin{array}{c}\mathrm{CuSO}_{4} \\
4 \%\end{array}$ & $\begin{array}{l}\text { Pre- } \\
\text { Mordantin } \\
\quad \mathrm{g}\end{array}$ & 0.8207 & -9.33 & 3.26 & 13.87 & 14.23 & 0.66 \\
\hline $\begin{array}{c}\mathrm{CuSO}_{4} \\
4 \% \\
\end{array}$ & $\begin{array}{c}\text { Post- } \\
\text { Mordantin }\end{array}$ & 0.1748 & -1.57 & -3.63 & 1.11 & 3.49 & 3.24 \\
\hline
\end{tabular}

Journal of Applied and Emerging Sciences Vol (10), Issue (01)
Figure 2 ( $\mathrm{a}$ and $\mathrm{b}$ ) have shown the K/S values of Lyocell fabric with mordant (ferrous sulfate and copper sulfate) at the concentration of $2 \%$ and $4 \%$. The figure showed that the K/S values of dyed Lyocell with mordant ferrous sulfate have higher values at both concentrations than copper sulfate in both mordanting methods. Colored bars in the figure have represented the outcomes of shade difference at both concentrations with the utilization of both mordants in both Mordanting methods. The highest K/S value i.e. 4.56, was achieved at concentration of $4 \%$ with ferrous sulfates whereas the lowest $\mathrm{K} / \mathrm{S}$ value (0.17) with copper sulfate at concentration $4 \%$ in the post-Mordanting method.
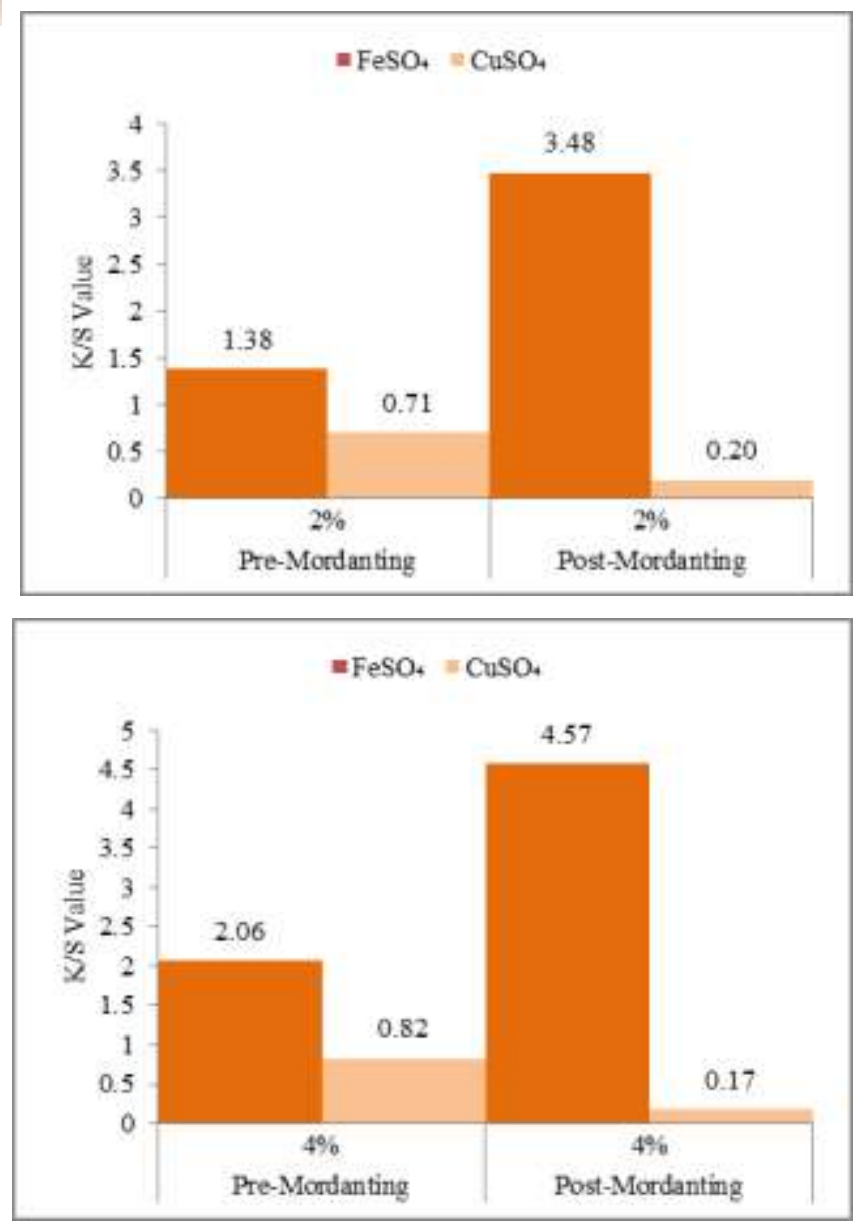

Figure 2 ( $\mathrm{a}$ and $\mathrm{b}$ ) Color strength (K/S values) of dyed Tencel samples in pre-Mordanting and post-Mordanting methods on $2 \%$ and $4 \%$ of the concentration

\section{B Color Fastness Properties of Dyed Lyocell:}

Extracted dye from orange peel has contributed proper washing, light, rubbing, and perspiration fastness properties with ferrous sulfate and copper sulfate on Lyocell fabric.

1) Light Fastness: Figure 3 (a) reveals the light fastness of Lyocell fabric, orange peel, and light ferrous sulphate and copper sulfate dyed $2 \%$. It has been 
observed that ferrous sulfate has excellent luminic stiffness than copper sulfate. Through ferrous sulfate, the color does not change and the color does not fade. In Figure 3(b), after dyeing sulfates with a concentration of $4 \%$, the highest luminous degree (45 ) is available in the post- Mordanting method, while the lightness of copper sulfate is lowest at 2\% (3-5). The results show that the sulfates, which are suitable for dyeing by post- Mordanting method, are ideal for the medium concentration of $4 \%$.
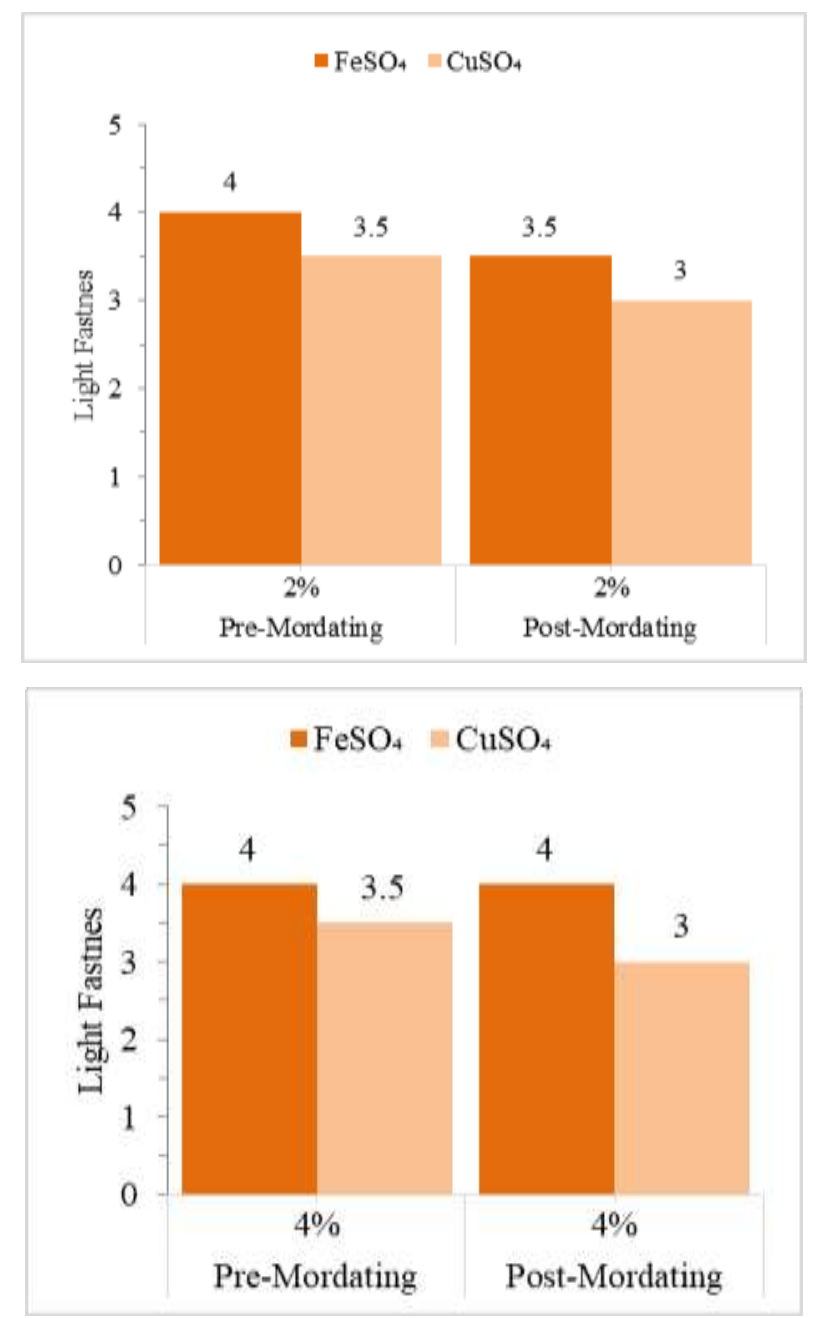

Figure 3(a and b) Light fastness properties of dyed Tencel fabric with two different mordants on $2 \%$ and $4 \%$ of concentration through pre and post-Mordanting methods

2) Washing Fastness: Figure 4(a) shows the wash fastness effect of the dyed Lyocell fabric. Compared with copper sulfate, sulfate has the highest washing fastness value. However, at a concentration of $4 \%$, the result is better (4-5). With copper sulfate, the result is the lowest value (3-4), especially at a concentration of $2 \%$. There is a slight change in color for all samples (4-5). Figure 4 (b) also shows that the chemical ferrous sulfate is much better in copper sulfate at a concentration of $4 \%$.
3) Rubbing Fastness (Dry and Wet): Figures 5 (a) and b show the frictional fastness of Lyocell fabrics dyed with dyes extracted from orange peel, with concentrations of $2 \%$ and $4 \%$. The mordant ferrous sulfate shows good grade (3-4) dry wipe sand and wet friction in both percentages. Mordant sulfate copper showed good wet and dry friction fastness in both mordant methods, with concentrations of $2 \%$ and $4 \%$. In addition, the results show that dry friction is better than wet friction. Copper sulfate has a good effect compared with ferrous sulfate in both concentrations. The reason for the grade difference here depends on the strength of the K/S value, and the higher the color intensity, the higher the friction.
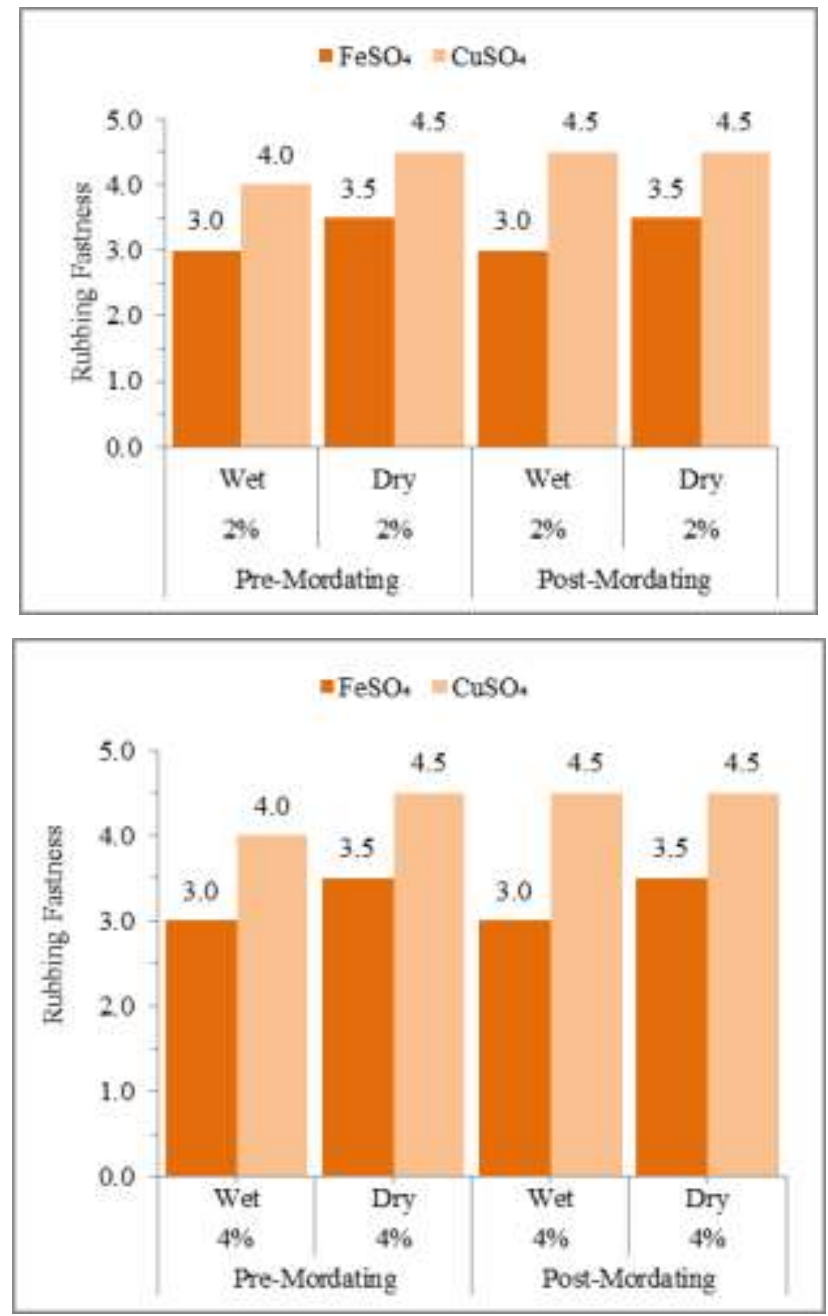

Figure 5(a and b) Rubbing fastness properties (dry and wet) of dyed Tencel fabric with two different mordants on $2 \%$ and $4 \%$ of concentration through pre and post-Mordanting methods

\section{CONCLUSION}

In this study, Lyocell fabrics were dyed with orange peel. The dye is extracted from the orange peel by water extraction. The color strength and washing, light, and friction fastness characteristics of Lyocell fabric were analyzed by two agents, 


\section{DOI: https://doi.org/10.36785/BUITEMS.JAES.306}

sulfate and copper sulfate. The effect of Chroma was evaluated using the pre-Mordanting method and postMordanting method, respectively, by concentrations of $2 \%$ and $4 \%$. Both animals showed good results in Lyocell fabrics. ferrous sulfate, however, is better than copper sulfate. Overall results showed that iron sulfate was a better choice for Lyocell fabrics in post-Mordanting with a concentration of $4 \%$. It also has good coloring efficiency (K/S: 4.56), and washing (4-5), light (5), friction (3-4) and sweat (4-5). Also, Lyocell fabrics dyed with natural orange peel contribute to environmental safety and enhanced human health.

\section{ACKNOWLEDGMENT}

The study was supported by the Central University Foundation for Basic Research (No. 17D310503) and the National Natural Science Foundation (No. 51403032).

\section{REFERENCES}

[1] A. Kechi, R. Chavan, and R. Moeckel, "Dye yield, color strength and dyeing properties of natural dyes extracted from Ethiopian dye plants," Textiles and Light Industrial Science and Technology, vol. 2, no. 3, pp. 137-145, 2013.

[2] S. Adeel, S. Ali, I. A. Bhatti, and F. Zsila, "Dyeing of cotton fabric using pomegranate (Punica granatum) aqueous extract," Asian Journal of Chemistry, vol. 21, no. 5, p. 3493, 2009.

[3] N. Patel, "6. NATURAL DYE BASED SINDOOR BY NK PATEL," Life Sciences Leaflets, vol. 11, pp. 355 to 362-355 to 362, 2011.

[4] S. Kulkarni, U. Bodake, and G. Pathade, "Extraction of Natural Dye from Chili (Capsicum Annum) for Textile Coloration," Universal Journal of Environmental Research \& Technology, vol. 1, no. 1, 2011.

[5] F. Rehman, N. Sanbhal, T. Naveed, A. Farooq, Y. Wang, and W. Wei, "Antibacterial performance of Tencel fabric dyed with pomegranate peel extracted via ultrasonic method," Cellulose, vol. 25, no. 7, pp. 4251-4260, 2018.

[6] M. Shahid and F. Mohammad, "Perspectives for natural product based agents derived from industrial plants in textile applications-a review," Journal of cleaner production, vol. 57, pp. 2-18, 2013.

[7] F. REHMAN, T. NAVEED, M. NADEEM, and W. WEI, "Study on Tencel Fabric Dyeing with Pomegranate Peel Natural Dyes," Asian Journal of Chemistry, vol. 29, no. 10, pp. 2279-2284, 2017.

[8] J. S. Jung, "Natural Dyeing of Cotton and Silk with Red Pigment Extract from Safflower," International
Journal of u-and e-Service, Science and Technology, vol. 9, no. 8, pp. 161-168, 2016.

[9] A. Davulcu, H. Benli, Y. Şen, and M. İ. Bahtiyari, "Dyeing of cotton with thyme and pomegranate peel," Cellulose, vol. 21, no. 6, pp. 4671-4680, 2014.

[10] P. Lokesh and M. Swamy, "Extraction of natural dyes from Spathodea campanulata and its application on silk fabrics and cotton," Der Chemica Sinica, vol. 4, no. 1, pp. 111-115, 2013.

D. Mahanta and S. Tiwari, "Natural dye-yielding plants and indigenous knowledge on dye preparation in Arunachal Pradesh, northeast India," Current science, pp. 1474-1480, 2005.

[12] K. Sachan and V. Kapoor, "Optimization of extraction and dyeing conditions for traditional turmeric dye," 2007.

Z. M. Win and M. M. Swe, "Purification of the natural dyestuff extracted from Mango bark for the application on protein fibers," World Acad Sci Eng Technol, vol. 22, pp. 536-540, 2008.

[14] A. K. Samanta and P. Agarwal, "Application of natural dyes on textiles," 2009.

[15] P. S. Vankar, "Dyeing Cotton, Silk and Wool yarn with extract of Garcinia mangostana pericarp," Journal of Textile and Apparel, Technology and Management, vol. 6, no. 1, 2009.

[16] S. Ali, N. Nisar, and T. Hussain, "Dyeing properties of natural dyes extracted from eucalyptus," Journal of the Textile Institute, vol. 98, no. 6, pp. 559-562, 2007.

[17] M. Kamel, H. Helmy, and N. El Hawary, "Some studies on dyeing properties of cotton fabrics with crocus sativus (Saffron flowers) using an ultrasonic method," Journal of Natural Fibers, vol. 6, no. 2, pp. 151-170, 2009.

[18] A. Curl and G. Bailey, "Orange Carotenoids, Part IComparison of Carotenoids of Valencia Orange Peel and Pulp, Part II-Carotenoids Aged Canned Valencia Orange Juice," Journal of Agricultural and Food Chemistry, vol. 4, no. 2, pp. 156-162, 1956.

[19] V. Oreopoulou and C. Tzia, "Utilization of plant byproducts for the recovery of proteins, dietary fibers, antioxidants, and colorants," in Utilization of byproducts and treatment of waste in the food industry: Springer, 2007, pp. 209-232.

[20] M. Moussaid, M. Lacroix, J. Nketsia-Tabiri, and C. Boubekri, "Phenolic compounds and the colour of oranges subjected to a combination treatment of waxing and irradiation," Radiation Physics and Chemistry, vol. 57, no. 3-6, pp. 273-275, 2000. 
DOI: https://doi.org/10.36785/BUITEMS.JAES.306

[21] X. Hou, X. Chen, Y. Cheng, H. Xu, L. Chen, and Y. Yang, "Dyeing and UV-protection properties of water extracts from orange peel," Journal of cleaner production, vol. 52, pp. 410-419, 2013.

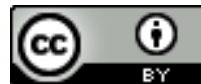

Journal of Applied and Emerging

Sciences by BUITEMS is licensed under a Creative Commons Attribution 4.0 International License. 